\title{
Comparative evaluation of computer assisted surgery of cystectomy of children's liver
}

\author{
Bulat Dzhenalaev $^{1}$, Sagidulla Dosmagambetov ${ }^{1}$, Aigerim Esenkulova1, Oksana \\ Zainullina $^{1}$, Michail Belyaev ${ }^{1}$, Karaman Suyungarin ${ }^{1}$
}

West Kazakhstan state medical University of Marat Ospanov, Aktobe, Kazakhstan

This work is licensed under a Creative Commons Attribution 4.0 International License

\section{UDC: 616.36-002.951.21-089-053.2}

\section{J Clin Med Kaz 2017; 3(45 Suppl 3):35-38}

Автор для корреспонденции: Есенкулова А.С., Западно-Казахстанский государственный университет имени Марата Оспанова, Актюбинский медицинский центр «детский стацинар», кафедра детской хирургии. Адрес: 030012, квартал Промзона 471, Актобе, Казахстан. Телефон: +7(705) 537-91-13

E-mail: Esenkul_aiko@mail.ru

\section{ABSTRACT}

Objective: a comparative evaluation of the results of the nearest postoperative period assisted surgery and the traditional methods of treatment of hepatic echinococcosis in children.

Methods. Based on the results of treatment of 92 children with hepatic echinococcosis, treated in the clinic of pediatric surgery in West Kazakhstan medical University named after Marat Ospanov in the period from 2014 to 2017. In the surgical treatment of hydatid cysts of the liver methods of endovideosurgery was used in 63 children (the main group) and open cystectomy liver in 29 children (comparison group).

The dynamics of the patients with echinococcosis of the liver in the immediate postoperative period after endovideosurgical and open cystectomy were evaluated by the following criteria: the terms of relief of pain syndrome (was used a numerical rating scale of pain assessment), the timing of normalization of body temperature and peripheral blood, timing of restoration of function of the gastrointestinal tract, the length of stay of patients in the intensive care unit, timing of recovery of motor activity, timing of removal of drains from the abdominal cavity, the length of hospital stay.

Results. The dynamics of the patients in the nearest postoperative period after cystectomy assisted surgery of the liver showed that in earlier periods was the relief of pain, normalization of body temperature, peripheral blood, restoration of the gastrointestinal tract, decreased length of stay in the intensive care unit, recovery of motor activity, at an earlier date removed drainage of the abdominal cavity, decreased time of inpatient treatment. Recurrence of the disease was not

Conclusion: Comparative evaluation of computer assisted surgery is cystectomy in conjunction with lymphotropic therapy with an open echinococcectomy showed less invasiveness of endovideosurgical technology, high efficiency and ability to perform echinococcectomy of the front not only localization, but also posterior-diaphragmatic. Carried out lymphotropic therapy contributes to a softer postoperative period.

Keywords: hydatid cyst of the liver - endovideosurgical echinococcectomy - postoperative period.

ТҰЖЫРЫМДАМА

БАЛАЛАРДАҒЫ БАУЫР ЭНДОВИДЕОХИРУРГИЯЛЫҚ ЭХИНОКОККЭКТОМИЯСЫНЫН САЛЫСТЫРМАЛЫ БАҒАЛАУЫ

Дженалаев Б.К. ${ }^{1}$, Досмагамбетов С.П. ${ }^{1}$, Есенкулова А.С. ${ }^{1}$, Зайнуллина О.Р. ${ }^{1}$, Беляев М.М. ${ }^{1}$, Суюнгарин К.К. ${ }^{1}$

${ }^{1}$ М.Оспанов атындағы Батыс Қазақстан Мемлекеттік медицина университет, қ. Ақтөбе, Қазақстан

Мақсаты: Балалардағы бауыр эхинококкозы жайында жасалған эндовидеохирургиялық және дәстүрлі емдеу әдістерін пайдаланғаннан кейін жақын операциядан кейінгі кезеңінің салыстырмалы бағалауы өткізілді.

Зерттеудің әдістері. Жұмыс Марат Оспанов атындағы БҚКМУ балалар хирургиясы клиникасында бауыр эхинококкозы бар 92 баладғы 2014-2017 жылдар аралығында емдеу нәтижелерінде негізделген. Бауыр эхинококкозының хирургиялық емдеу кезінде эндовидеохирургиялық әдісі 63 балада (негізгі топ), ал ашық эхинококкэктомия 29 балада (салыстыру тобы) пайдаланылды. Жақын операциядан кейінгі кезеңде 
эндовидеохирургиялық және ашық түрде жасалған операциядан кейін науқастардың динамикасын төмендегі критерийлермен бағаладық: ауырсыну мерзімін шеттету мерзімі (сандык рейтингтік аура шкаласымен бағалау), дене қызуының, перифериялық қан көрсеткіштерінің қалпына келуі, асқазан-ішек жолдары жұмысының қалпына келуі, реанимация бөлімшесінде болу мерзімі, қимыл белсенділігінің қалпына келу мерзімі, құрсақ қуысынан дренажды алу мерзімі, стационарлық ем алу мерзімі.

Нәтижелері. Науқастың динамикасын эндовидеохирургиялық бауыр эхинококкэктомиядан жақын кейінгі кезеңде ауырсыну синдромының жоюы дене қызуының, қан көрсеткіштерінің қысқа мерзімде қалпына келуі, асқазан-ішек жолдарының қалпына келуі, реанимация бөлімінде болуы, қимыл белсенділегінің қалпына келуі, құрсақ құысынан дренажды неғұрлым ерте ауын, ауруханада емделу мерзімін қыскаратындығын көрсетті. Аурудың рецидиві болған жоқ.

қорытынды: лимфотропты емімен бірге жасалған эндовидеохирургиялық эхинококкэктомия және ашық түрде жасалған эхинококкэктомиясының салыстырмалы бағалауы эндовидеохирургиялық технологиясының инвазиясының төмен әсерлігі эхинококкэктомияны тек алдынғы оқшалау емес, сонымен қатар артқы-диафрагмалды оқшалауыны жасау мүмкіндігі бар екенін көрсетті. Лимфотропты емі операциядан кейінгі кезеңінің неғұрлым жеңіл өтуіне ықпал етеді.

Маңызды сөздер: бауыр эхинококкозы - эндовидеохирургиялық эхинококкэктомия - операциядан кейінгі кезең.

\section{PEЗЮME}

СРАВНИТЕЛЬНАЯ ОЦЕНКА ЭНДОВИДЕОХИРУРГИЧЕСКОЙ ЭХИНОКОККЭКТОМИИ ПЕЧЕНИ У ДЕТЕЙ

Дженалаев Б.К. ${ }^{1}$, Досмагамбетов С.П. ${ }^{1}$, Есенкулова А.С. ${ }^{1}$, Зайнуллина О.Р. ${ }^{1}$, Беляев М.М. ${ }^{1}$, Суюнгарин К.К. ${ }^{1}$

1 Западно-Казахстанский государственный медицинский университет имени Марата Оспанова, г. Актобе, Казахстан

Цель исследования: провести сравнительную оценку результатов ближайщего послеоперационного периода эндовидеохирургического и традиционного методов лечения эхинококкоза печени у детей.

Методы. Работа основана на результатах лечения 92 детей с эхинококкозом печени, находившихся в клинике детской хирургии ЗКГМУ им.Марата Оспанова в период 2014 - 2017 годы. При хирургическом лечении эхинококковых кист печени методы эндовидеохирургии были применены у 63 детей (основная группа), открытые эхинококкэктомии печени - у 29 детей (группа сравнения). Динамику состояния больных с эхинококкозом печени в ближайшем послеоперационном периоде после эндовидеохирургической и открытой эхинококкэктомии оценивали по следующим критериям: срокам купирования болевого синдрома (была использована цифровая рейтинговая шкала оценки боли), срокам нормализации температуры тела и показателей периферической крови, срокам восстановления фрункции желудочно-кишечного тракта, срокам пребывания больных в отделении реанимации, срокам восстановления двигательной активности, срокам удаления дренажей из брюшной полости, срокам стационарного лечения.

Результаты. Динамика состояния больных после эндовидеохирургической эхинококкэктомии печени в ближайщем послеоперационном периоде показала, что в более ранние сроки происходило купирование болевого синдрома, нормализации температуры тела, показателей периферической крови, восстановление функций желудочно-кишечного тракта, уменьшились сроки пребывания в отделении реанимации, сроки восстановления двигательной активности, в более ранние сроки удалялся дренаж из брюшной полости, сократились сроки стационарного лечения. Рецидивов заболевания не было

Выводы. Сравнительная оценка эндовидеохирургической эхинококкэктомии в сочетании с лимфотропной терапией с открытой эхинококкэктомией показала меньшую инвазивность эндовидеохирургической технологии, высокую его эффективность, возможность выполнить эхинококкэктомию не только передней локализации, но и задне-диафрагмальной. Проводимая лимфотропная терапия способствует более мягкому течению послеоперационного периода.

Ключевые слова: эхинококкоз печени - эндовидеохирургическая эхинококкэктомия - послеоперационный период

\section{Введение}

Эхинококкоз - широко распространенное хроническое паразитарное заболевание человека в нашей стране $[1,3]$. По данным литературы тенденции к снижению частоты встречаемости данной патологии в последнее деятилетие не отмечается [4]. Существующие открытые методы хирургического лечения эхинококковых кист печени не всегда удовлетворяют хирургов. В последние три десятилетия отмечается активное применение методов эндовидеохирургии в лечении большинства заболеваний органов грудной и брюшнойполости, в Т.ч. ипри эхинококкозе пчени. В опубликованных работах в основном приведены результаты применения методов эндовидеохирургии при эхинококкозе печени у взрослых, а результаты применения данного метода у детей носят единичный характер [2, 5]. Требуется дальнейшее сравнительное изучение результатов эндовидеохирургической эхинококкэктомии печени у детей.

Цель исследования - провести сравнительную оценку результатов ближайщего послеоперационного периода эндовидеохирургического и традиционного методов лечения эхинококкоза печени у детей.

\section{Материал и методы}

Работа основана на результатах лечения 92 детей с эхинококкозом печени, находившихся в клинике детской хирургии ЗКГМУ им.Марата Оспанова в период 2014 - 2017 годы. Возраст детей составил 4-17 лет, из них от 11 до 17 лет - 56 детей. От 4 до 7 лет - 8 детей, от 7 до 10 лет - 28 детей. В плановом порядке оперировано - 89, в экстренном - 3. Локализация кист печени была следующей: S7-8 у 29 детей, S6-7 у 16 детей, S5 у 16 детей, S2 у 14 детей, S3 у 4 детей, S4 у 13 детей. По размеру кисты распределились следующим образом: малые кисты (до 5 см) у - 25, средние (5-10см) у - 52 детей, большие (более $10 \mathrm{~cm}$ ) у - 15 больных. У 79 больных кисты печени были одиночными, у 13 множественные. При хирургическом лечении эхинококковых кист печени методы эндовидеохирургии были применены у 63 детей (основная группа), открытая эхинококкэктомия печени - у 29 детей (группа сравнения). Диагноз эхинококкоза устанавливался на основании клинических, лабораторных и иммунологических исследований, УЗИ печени, МРТ. С целью предоперационной подготовки ребенку проводилась антигельминтная терапия курсом 14 дней. Продолжительность операций с применением эндовидеохирургических технологий составила 554 мин, при открытой операции - 775 мин. Для общей анестезии использовали 20\% оксибутират натрия, кетамин, калипсол. Эндовидеохирургические операции проводились на фоне ИВЛ воздушно-кислородной смесью. Релаксация осуществлялась аркуроном и дитилином. Основные этапы операции были одинаковыми в обеих группах, за исключением специфических особенностей. 
Основные этапы эндовидеохирургической эхинококкэктомии печени были следующими:

1. Наложение пневмоперитонеума, введение троакаров для оптики и манипуляционных инструментов.

2. Пункция кисты, аспирация содержимого, внутрикистозная антигельминтная обработка $1 \%$ раствором бетадина (рисунок 1)

3. Рассечение фиброзной капсулы (рисунок 2)

4. Окончательная аспирация жидкого содержимого кисты (рисунок 3)

5. Вакуум экстракция хитиновой оболочки (рисунок 4)

6. Дренирование полости кисты и подпеченочного тпространства (рисунок 5)

7. Катетеризация круглой связки печени для проведения регионарной лимфотропной терапии (рисунок 6).
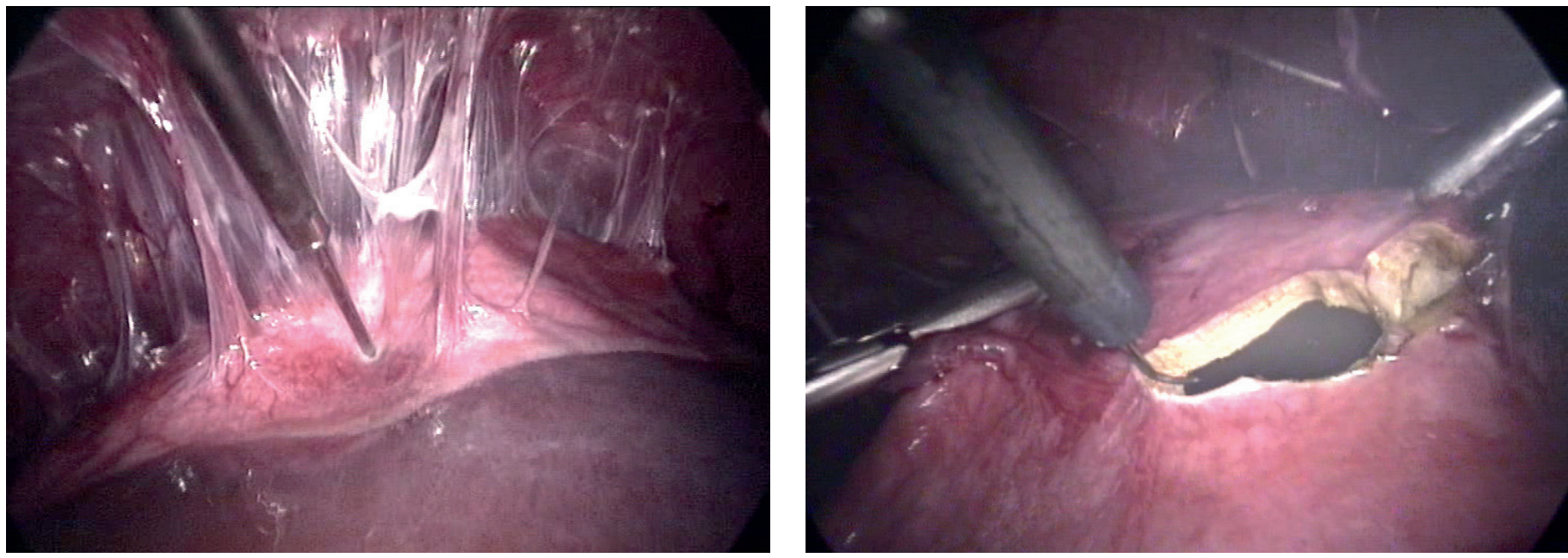

Рисунок 1- Пункция кисты

Рисунок 2- Рассечение фиброзной капсулы

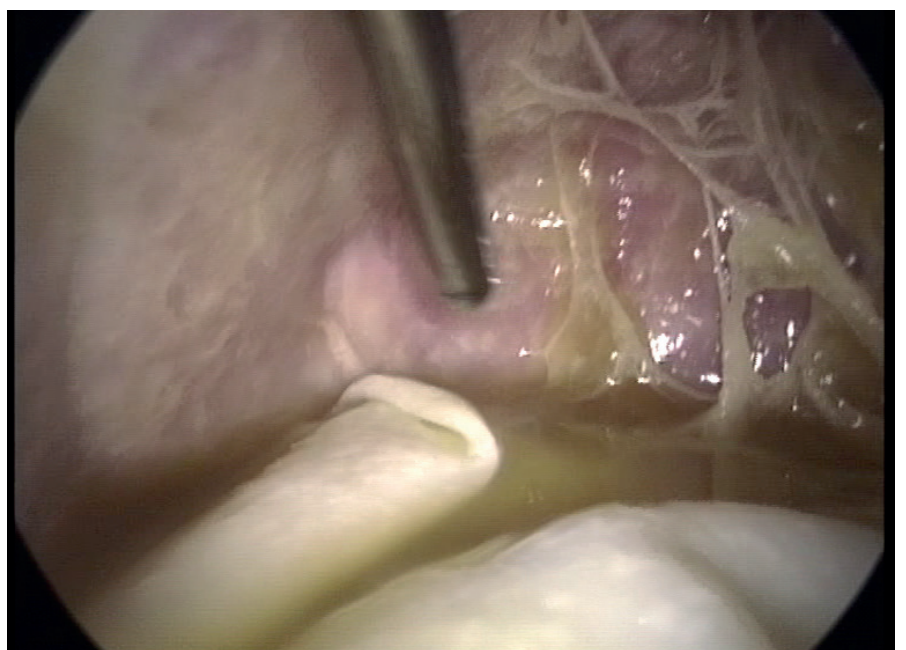

Рисунок 3- Окончательная аспирация жидкого содержимого кисты

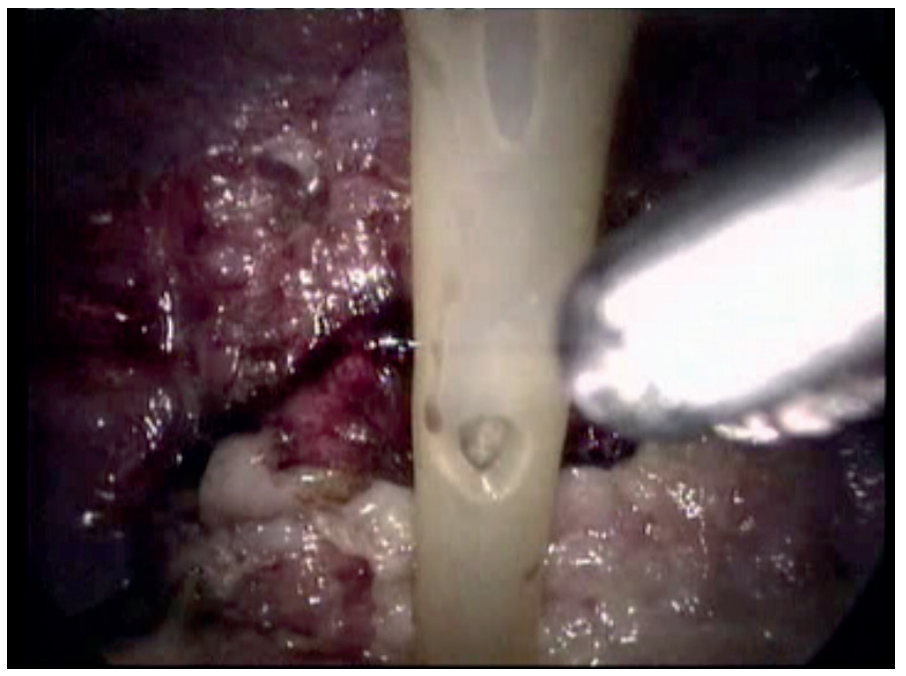

Рисунок 5- Дренирование полости кисты

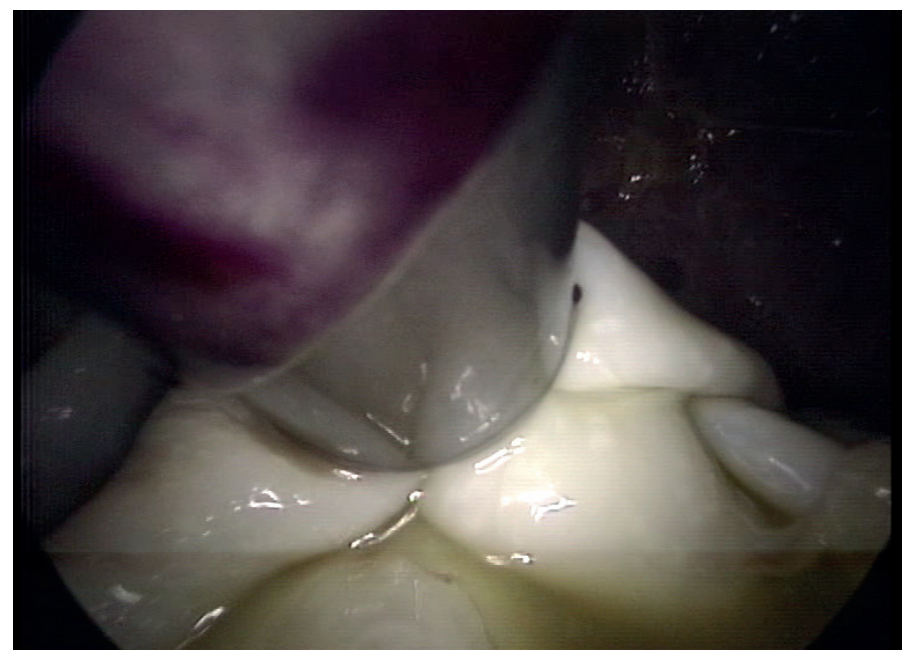

Рисунок 4- Вакуум экстракция хитиновой оболочки

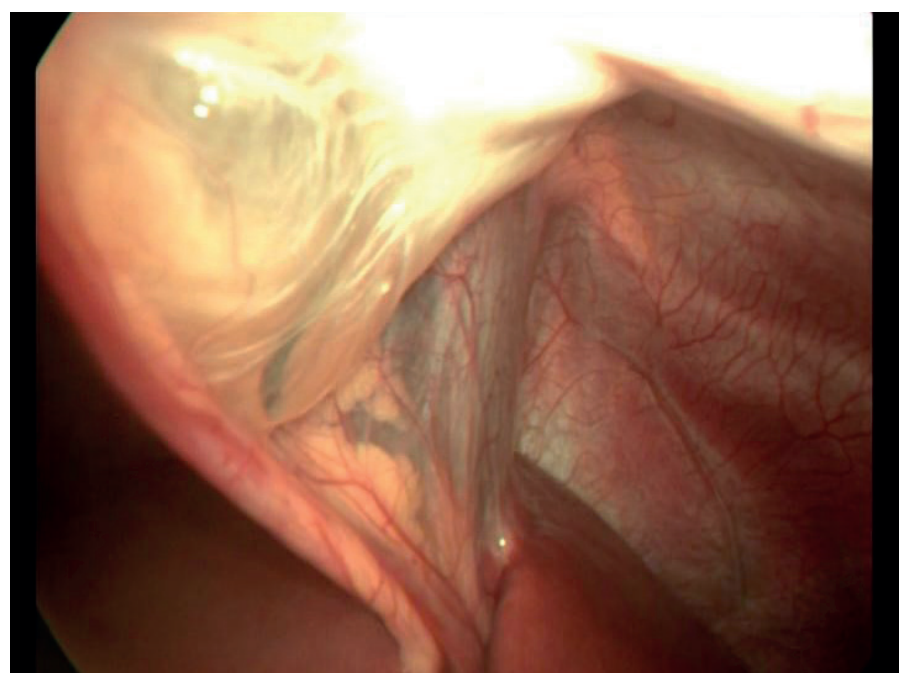

Рисунок 6- Катетеризация круглой связки печени для проведения лимфотропной терапии 
Основными этапами открытой эхинококкэктомии печени были следующие:

1. Лапаротомия (по Федорову, верхне-срединная лапаротомия).

2. Пункция кисты, аспирация содержимого, внутрикистозная антигельминтная обработка $1 \%$ раствором бетадина

3. Рассечение фиброзной капсулы

4. Окончательная аспирация жидкого содержимого кисты

5. Удаление хитиновой оболочки

6. Дренирование остаточной полости кисты и подпеченочного пространства.

Динамику состояния больных с эхинококкозом печени в ближайшем послеоперационном периоде после эндовидеохирургической и открытой эхинококкэктомии оценивали по следующим критериям: срокам купирования болевого синдрома (была использована цифровая рейтинговая шкала оценки боли), срокам нормализации температуры тела и показателей периферической крови, срокам восстановления функции желудочно-кишечного тракта, срокам пребывания больных в отделении реанимации, срокам восстановления двигательной активности, срокам удаления дренажей из брюшной полости, срокам стационарного лечения.

\section{Результаты}

Динамика состояния больных в ближайщем послеоперационномпериоде послеэндовидеохирургической эхинококкэктомии печени показала, что купирование болевого синдрома происходило в среднем на 3,5 $\pm 0,5$ сутки, нормализация температуры тела на 2,5 $\pm 0,3$ сутки, показателей периферической крови на $3,2 \pm 0,3$ сутки, восстановление функций желудочно-кишечного тракта на $2,3 \pm 0,5$ сутки, срок пребывания в отделении реанимации - 0,9 $\pm 0,3$ сутки, сроки восстановления двигательной активности - на $1,7 \pm 0,2$ сутки, дренаж из брюшной полости в связи с прекращением отделяемого удалялся на $3,6 \pm 0,7$ сутки, сроки стационарного лечения составили $10,5 \pm 1$ дней. Рецидивов заболевания не было. В группе сравнения у больных после открытой эхинококкэктомии печени купирование болевого синдрома происходило в среднем на $5,2 \pm 0,7$ сутки, нормализация температуры тела на 3,6 $\pm 0,5$ сутки, показателей периферической крови на $5 \pm 0,2$ сутки, восстановление функций желудочно-кишечного тракта на $4,2 \pm 0,2$ сутки, срок пребывания в отделении реанимации - $3 \pm 0,4$ суток, сроки восстановления двигательной активности - на 2,5 $\pm 0,4$ сутки, нормализация показателей крови - на $5 \pm 0,2$ сутки, дренаж из брюшной полости в связи с прекращением отделяемого удалялся на 4,6 $\pm 0,6$ сутки,

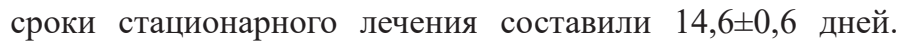
Рецидив заболевания отмечался у 1 больного.

\section{Обсуждение}

Осложнений, связанных с применением эндовидеохирургическихтехнологий,конверсийнаоткрытуюоперацию не было. Предварительная антигельминтная терапия снижает внутрикистозное напряжение, что позволяет выполнить эндовидеохирургическую эхинококкэктомию с соблюдением принципов «апаразитарности». В основной группе было 29 больных с задне-диафрагмальной локализацией кист, которые ранее считались противопоказанием для выполнения эндовидеохирургической эхинококкэктомии. Накопленный опыт, улучшение техники выполнения эндовидеохирургической операции, а также собственные разработки клиники позволили выполнить эхинококкэктомию при указанных локализациях [6].

Меньшая инвазивность эндовидеохирургической эхинококкэктомии печени оказывает соответственно меньшее влияние на функциональное состояние организма больных детей, что отразилось на особенностях течения ближайщего послеоперационного периода. В более ранние сроки отмечается купирование болевого синдрома, восстановление двигательной активности, восстановление моторики кишечника в основной группе больных. Проведение операции в сочетании с лимфотропной терапией способствовало созданию достаточной концентрации антибиотика в очаге поражения, улучшению лимфодренажа, что клинически проявилось в более ранней нормализации температуры тела, показателей крови, более раннему прекращению отделяемого по дренажу [7].

\section{Выводы}

Таким образом, сравнительная оценка эндовидеохирургической эхинококкэктомии в сочетании с лимфотропной терапией с открытой эхинококкэктомией показала меньшую инвазивность эндовидеохирургической технологии, высокую его эффективность, возможность выполнить эхинококкэктомию не только передней локализации, но и задне-диафрагмальной. Проводимая лимфотропная терапия способствует более «мягкому» течению послеоперационного периода.

\section{Литература}

1. Pulatov AT. Jehinokokkoz v detskom vozraste (Echinococcosis in childhood) [in Russian] Medicina. 2004. 224 p.

2. Gul'muradov TG, Amonov ShSh, Sangov DS. Minimal'no-invazivnoe hirurgicheskoe lechenie jehinokokkoza pecheni (Minimally invasive surgical treatment of liver echinococcosis) [in Russian]. Vestnik IPOvSZ RT. 2007;4

3. Ordabekov SO, Akshulakov SK., Kulakeev OK. Jehinokokkoz cheloveka: uchebnoe posobie (Echinococcosis rights: a manual) [in Russian]. Jevero. 2009. 512 p.

4. Domashenko ON., Shatalov AD., Panieva DS. Jehinokokkoz pecheni: diagnostika, lechebnaja taktika (Echinococcosis of the liver: diagnosis, treatment tactics) [in Russian]. Medicinskie nauki. Klinicheskaja medicina. 2016; 3 (39):35.

5. Abdisamatov BS. Sovremennye napravlenija v hirurgicheskom lechenii jehinokokkoza pecheni (Modern directions in the surgical treatment of liver echinococcosis) [in Russian]. Sovremennaja medicina: aktual'nye voprosy: sb.st. po mater. LII-LIII nauch.prakt.konf. Novosibirsk: SibAK. 2016. 91-98 p.

6. Kotlobovskij VI., Dzhenalaev BK, Dosmagambetov, SP, Dzhenalaev DB, Ergaliev AE. Patent RK na izobretenie №19525, Sposob operacionnogo dostupa pri laparoskopicheskoj jehinokokkjektomii pecheni (Mode of operative access for laparoscopic liver echinococcemia) [in Russian]. Astana. 2007.

7. Ajnazarov MS. Jehinokokkoz, porazhenie VII-VIII segmentov pecheni, profilaktika oslozhnenij (Echinococcosis, involvement of VII-VIII liver segments, prevention of complications) [in Russian].Vestnik Kyrgysko-Rossijskogo Slavjaskogo universiteta. 2013; 13(1):135-137. 